\title{
Post-mortem examination and laboratory-based analysis for the diagnosis of bovine tuberculosis among dairy cattle in Ecuador
}

\author{
Freddy Proaño-Pérez ${ }^{\mathrm{a}, \mathrm{b}, 1}$, Washington Benitez-Ortiz ${ }^{\mathrm{a}, \mathrm{b}, \mathrm{c}, 2}$, Daniel Desmecht ${ }^{\mathrm{d}, 3}$, \\ Marco Coral ${ }^{\mathrm{c}, 4}$, Julio Ortiz ${ }^{\mathrm{c}, 4}$, Lenin Ron ${ }^{\mathrm{a}, 5}$, Françoise Portaels ${ }^{\mathrm{e}, 6}$, Leen Rigouts ${ }^{\mathrm{e}, \mathrm{f}, 7}$, \\ Annick Linden $\mathrm{b}, *, 8$ \\ a International Centre for Zoonoses, Central University of Ecuador, Quito, Ecuador \\ b Department of Infectious and Parasitic Diseases, Faculty of Veterinary Medicine, University of Liege, Belgium \\ c Faculty of Veterinary Medicine, Central University of Ecuador, Quito, Ecuador \\ d Department of Morphology and Pathology, Faculty of Veterinary Medicine, University of Liege, Belgium \\ e Mycobacteriology Unit, Department of Microbiology, Institute of Tropical Medicine, Antwerp, Belgium \\ f Department of Pharmaceutical, Veterinary and Biomedical Sciences, University of Antwerp, Antwerp, Belgium
}

\section{A R T I C L E I N F O}

\section{Article history:}

Received 6 July 2010

Received in revised form 26 April 2011

Accepted 29 April 2011

\section{Keywords:}

Veterinary inspection

In vitro culture

PCR

Mycobacterium bovis

\begin{abstract}
A B S T R A C T
Veterinary inspection in slaughterhouses allows for the detection of macroscopic lesions reminiscent of bovine tuberculosis, but the presence of Mycobacterium bovis must be confirmed by laboratory methods. This study aimed at comparing the performances of the standard diagnostic tools used to identify $M$. bovis in tissue specimens sampled from suspicious animals. During a two years period, 1390 cattle were inspected at the Machachi abattoir in the Mejia canton - Ecuador. A total of 33 animals with granulomatous lesions were detected, representing 2.33\% (16/687) and 2.42\% (17/703) animals examined in 2007 and 2008, respectively. Ninety-four tissue specimens were sampled and screened for the presence of mycobacteria. Acid-fast bacilli were identified in one third of the suspicious cattle (11/33) and suggestive microscopic lesions in $27.3 \%$ (9/33) of the samples examined by direct microscopy and histopathology, respectively. Culturing on Stonebrink medium and 16S-rRNA-based polymerase chain reaction (PCR) yielded 36.4\% (12/33) and 27.3\% (9/33) of positives, respectively. Compared to culture, other diagnostic procedures displayed a lower sensitivity, with $56.5 \%$ for PCR, and $43.5 \%$ for direct microscopy and histopathology; however, the specificity was higher (94.4\% for PCR and microscopy, and $97.2 \%$ for histopathology). We conclude that reliable post-mortem laboratory testing either requires the combination of a set of available diagnostic tools or necessitates the development of improved new-generation tools with better sensitivity and specificity characteristics.
\end{abstract}

(c) 2011 Elsevier B.V. All rights reserved.

\footnotetext{
* Corresponding author at: Department of Infectious and Parasitic Diseases, Faculty of Veterinary Medicine, University of Liege, Sart Tilman 20, Bât. B43a, B-4000 Liège, Belgium. Tel.: +32 4366 4051; fax: +32 4366 4565.

E-mail addresses: fproano-ciz@ac.uce.edu.ec, ciz-rectoradouc@andinanet.net (F. Proaño-Pérez), wbenitez-ciz@ac.uce.edu.ec (W. Benitez-Ortiz), daniel.desmecht@ulg.ac.be (D. Desmecht), chuckcora@hotmail.com (M. Coral), julioortiz88@hotmail.com (J. Ortiz), Iron-ciz@ac.uce.edu.ec
}

(L. Ron), fportaels@itg.be (F. Portaels), lrigouts@itg.be (L. Rigouts), a.linden@ulg.ac.be (A. Linden).

1 Participation: conception and design of the study, Executor of field survey, analysis of data, drafting the paper. Tel./fax: +59322904801.

2 Participation: conception and design of the field study, analysis of data, critical review and commenting on draft. Tel./fax: +593 22904801 .

3 Participation: laboratory work, critical review \& revision and commenting on draft. Tel.: +32 4366 4051; fax: +32 43664565 .

4 Participation: field study. Tel./fax: +59322904801. 


\section{Introduction}

Bovine tuberculosis (BTB) is present in most developing countries where surveillance and control activities are not or inadequately implemented (Cosivi et al., 1998). In Ecuador, there is no BTB control program in place. An apparent prevalence of $7.95 \%$ was observed among dairy cattle from large herds in 2004 (Proaño-Perez et al., 2006), and it increased to $8.63 \%$ three years later in the same region (Proaño-Pérez et al., 2009). Herd size was identified as an important risk factor in this husbandry system, and the number of skin-test-positive cases also increased significantly with cattle age (Proaño-Pérez et al., 2009).

BTB control programs consist of pasteurization of milk, meat hygiene control through macroscopic inspection at slaughter (veterinary inspection), and skin testing to detect and cull infected animals (Collins, 2006).

Cattle are mainly infected with $M$. bovis through inhalation of aerosolized droplets (Goodchild and Clifton-Hadley, 2001). However, the process by which exposure to infection can lead to a range of disease outcomes is not fully understood (Neill et al., 1994; Pollock et al., 2006). Not all infected cattle display gross lesions, but if present, they are often located in thoracic lymph nodes (Whipple et al., 1996) even in apparently healthy cattle. Lesions due to nontuberculous mycobacteria (NTM) can be easily mistaken for BTB lesions (Oloya et al., 2007). Consequently, laboratory approaches are important to confirm and identify the mycobacterial species involved.

Different methods can be used to identify the disease in humans and animals. Microscopic detection of mycobacteria is insensitive and does not permit the identification of the mycobacterial species involved. Culture of $M$. bovis can be more sensitive and allows for species identification, but is time consuming due to the slow growth of the bacilli (Mangiapan et al., 1996). Polymerase chain reaction (PCR) can reduce the time for detection and also identify the species.

The aim of this study was to compare currently available laboratory tools to diagnose BTB using abattoir samples taken during veterinary inspection, characterize the distribution of lesions observed in the organs of inspected cattle, and study the true prevalence of BTB.

\section{Materials and methods}

\subsection{Study design}

Veterinary inspection was carried out in 1390 slaughtered cattle from 112 different dairy farms at the abattoir of Machachi located in the Mejia canton $\left(0^{\circ} 27^{\prime} \mathrm{SL}\right.$ and $78^{\circ} 25^{\prime} \mathrm{WL}$ ), located in the major dairy cattle production

\footnotetext{
5 Participation: analysis of data, critical review and commenting on draft. Tel./fax: +59322904801.

6 Participation: critical review and revision and commenting on draft. Tel.: +32 32476551 .

7 Participation: conception and design of the study, analysis of data, critical review and revision and commenting on draft. Tel.: +32 32476551

8 Participation: conception and design of the study, analysis of data, critical review \& revision and commenting on draft.
}

area in northern Ecuador. There was no previous studies on BTB in this abattoir. In total, 29 interventions were performed at the slaughterhouse during the period from February to March in the years 2007 and 2008. Detailed post-mortem examination was performed in 687 and 703 cattle, respectively. In this study, all cattle were inspected during each intervention, and cattle originating from areas outside the Mejia canton were excluded. Individual data were recorded for each animal by the use of a questionnaire with a focus on age, breed, sex, name of the owner, origin of the animal and lesions found during the inspection. Five of the animals examined during the abattoir survey were previously identified as bovine comparative intradermal tuberculin test (CITT) reactors in a survey among dairy cattle in the Mejia canton (Proaño-Pérez et al., 2009).

\subsection{Post-mortem examination}

Detailed veterinary inspection was carried out on all cattle. The lungs, liver, spleen, kidney and mammary gland were palpated carefully and inspected externally and internally. Mandibular, retropharyngeal, tracheobronchial, mediastinal, hepatic, mesenteric and supramammary lymph nodes were sliced into thin sections $(2-3 \mathrm{~mm})$ and inspected in situ for detection of visible lesions.

\subsection{Samples}

Tissue specimens were taken from multiple organs using disinfected knives (i.e., chlorine 10\%) from all suspected animals for further laboratory-based diagnosis. We included all organs with visible lesions, and added lung tissue taken from the inferior lobe in all sampled cattle, even if no macroscopic lesions were visible. In total, 94 tissue samples were collected from 33 suspected cattle (2-8 specimens/animal, depending on the lesions found); 65 of them were sampled from tissues with visible gross lesions suggestive for mycobacterial infection, and the rest were samples without lesions taken from lungs.

All samples were collected in individual sterile tubes, stored in a cool box, and transported the same day to the Laboratory of Microbiology at the International Centre of Zoonoses, in Quito. Upon arrival, processing of samples was carried out using aseptic techniques in a biosafety cabinet to avoid cross-contamination between samples. In order to perform microscopy, PCR, and in vitro culture, approximately $5 \mathrm{~g}$ of tissue were stored at $-20^{\circ} \mathrm{C}$ in $2 \mathrm{~mL}$ Eppendorf ${ }^{\circledR}$ tubes containing Dubos broth (No. 0385-17-6, Difco Laboratories, Detroit, USA) supplemented with PANTA (Bactec PANTA plus kit No. 440476 4; Becton Dickinson, NJ, USA) to inhibit the growth of contaminants and to preserve the mycobacteria. During the international transport to Belgium the samples were packed in a cooler. All samples underwent 2 freeze-thaw cycles due to the storage and shipping prior to their final processing at the Mycobacteriology Unit, in the Institute of Tropical Medicine of Antwerp, Belgium. Duplicate samples that were stored in Ecuador had only one freeze-thaw cycle and were processed locally once the culture technique was implemented. 
In addition, about $1 \mathrm{~cm}^{3}$ of each sample was stored in $10 \%$ formalin for histopathologic analyses at the Department of Morphology and Pathology from the Faculty of Veterinary Medicine in the University of Liege, Belgium.

\subsection{Microscopy and in vitro culture}

Upon arrival in Antwerp, all samples for bacteriological examination were cut and homogenized in a sterile mortar with $2 \mathrm{~mL}$ of sterile phosphate buffered saline. In vitro culture was carried out after decontamination using the "reversed" Petroff method (Palomino and Portaels, 1998): 20 min incubation with $3 \mathrm{~mL}$ of $1 \mathrm{~N} \mathrm{HCl}$ followed by neutralisation with $3 \mathrm{~mL}$ of $1 \mathrm{~N} \mathrm{NaOH}$ and centrifugation for $20 \mathrm{~min}$ at $3000 \times \mathrm{g}$. The pellet was mixed with $2 \mathrm{~mL}$ sterile distilled water and inoculated onto Löwenstein-Jensen (LJ) (Parks, 1997), and Stonebrink medium (i.e. LJ without glycerol but supplemented with $0.4 \%$ sodium pyruvate). Isolates were identified as $M$. bovis by spoligotyping characterized by a typical lack of spacers 3, 9, 16 and 37-42 (Kamerbeek et al., 1997). For Ziehl-Neelsen (ZN) staining and subsequent microscopic inspection to detect acid-fast bacilli (AFB), a slide was prepared using 1 drop of the processed specimen. Stained slides were examined with a normal light microscope using objective $100 \times$ and immersion oil.

\subsection{Polymerase chain reaction}

DNA was extracted from the re-suspended pellet using the method developed by Mangiapan and colleagues (1996). A routinely-applied, nested PCR targeting the 165 ribosomal RNA gene was performed to detect DNA specific for the M. tuberculosis-complex using the following primers (Portaels et al., 1996): P1 (5'-TGCTTAACACATGCAAGTCG$\left.3^{\prime}\right)$ and P2 (5'-TCTCTAGACGCGTCCTGTGC-3') for the first run, and P3 (5'-AACCCGGACCTTCGTCGATG-3') with P9 (5'CATGTCTTGTGGTGGAAAGCGC- $3^{\prime}$ ) for the second run. Samples were considered positive to bovine tuberculosis when a band of $500 \mathrm{bp}$ was observed on a $2 \%(w / v)$ agarose gel.

\subsection{Histopathology}

Slides for histopathology examination were prepared using standard techniques, and processed for standard hematoxylin-eosin (HE) and ZN staining. A sample was considered positive if lesions characteristic for BTB were demonstrated (granulomatous inflammation associated with focal caseous necrosis or mineralization), or if AFB were observed in the ZN stain (Whipple et al., 1996).

\subsection{Statistical analysis}

The true prevalence (TP) based on detection of gross visible lesions was calculated using the RoganGladen's Equation (1978) under a Bayesian modelling approaches (Berkvens et al., 2006). The Rogan-Gladen equation describes the estimation of TP through the apparent prevalence $\left(P^{\prime}\right)$, and the $S e$, and $S p$ of a test $\left[P^{\prime}=T P S e+(1-T P)(1-S p)\right]$. Since there is no gold standard test, TP must be estimated imposing constraints on the parameters (Berkvens et al., 2006). Bayesian approach lets to incorporate external information by specifying prior distributions on the parameters, i.e., prior knowledge and/or beliefs regarding to $S e$ and Sp of necropsy (Enoe et al., 2000; Branscum et al., 2005). This approach makes possible inferences about $S e$ and $S p$ with 95\% probability interval (95\% PI) of necropsy used in this study. The prior distribution on Se was elicited from a previous study that considers the most likely value (modal), thus the $S e$ of necropsy was 0.8 with a 10 th percentile of 0.55 ; which is acceptable for this test and was chosen because a similar procedure during the necropsy was performed in the same lymph nodes (Norby et al., 2004), and based on the same measures through veterinary inspection to discard carcasses in Ecuador (Personal communication). The prior distribution for the $S p$ was elicited from the experience of veterinarian inspectors from the slaughterhouse of the Mejia canton, taking into account the presence of other infectious diseases causing lesions in lymph nodes specially in dairy cattle, thus a modal value of 0.95 with a 5 th percentile of 0.80 were set to model the uncertainty about Sp. The BetaBuster software (available at http://www.epi.ucdavis.edu/diagnostictest/) (Branscum et al., 2004) computed the two parameters of a Beta prior distributions based on the mode and one percentile for $S e$ and $S p$, i.e., Beta for $S e(5.28,2.07)$, and Beta for $S p(21.20,2.06)$. A binomial model was built and Bayesian estimation was done through Gibbs sampling in WinBUGS (Spiegelhalter et al., 1996). A burn-in phase of 1000 iterations was used and the model was run for another 10,000 iterations to obtain estimates. The outcomes were mean and percentiles (i.e., 2.5 and 97.5) sampled from the posterior distributions of $T P$, Se and $S p$. Three chains starting in different values were set and their convergence was analyzed through trace plot. Additionally the effect of different prior distributions for the parameters of the model was analyzed in order to evaluate how prior beliefs could affect the posterior estimates of TP, Se and $S p$. Seven scenarios were built assuming prior different beliefs about the parameters (Table 1 ): (Scenario 1 ) No prior constraints: $T P \sim \operatorname{Uniform}(0,1), S e \sim \operatorname{Uniform}(0,1)$ and $S p \sim$ Uniform (0, 1); (Scenario 2) Prior distributions for $S e$ and $S p$ uniformly distributed according to ranges suggested by Norby et al. (2004), and expert opinion of veterinaries in slaughterhouses $T P \sim$ Uniform $(0,1)$, $S e \sim$ Uniform $(0.51,0.98)$ and $S p \sim$ Uniform $(0.80,0.90)$; (Scenario 3) True prevalence constrained uniformly to values less that $10 \%$ and $S e$ and $S p$ with similar values to previous experiences $T P \sim$ Uniform $(0,0.10), S e \sim$ Uniform $(0.50,1.00)$ and $S p \sim$ Uniform $(0.70,1.00)$; (Scenario 4$)$ True prevalence constrained uniformly to values less that $5 \%$ and $S e$ and $S p$ with similar values to previous experiences but widen: $T P \sim$ Uniform $(0,0.05), S e \sim$ Uniform $(0.40$, 1.00 ) and $S p \sim$ Uniform $(0.60,1.00)$; (Scenario 5) Assuming that $S e$ of the necropsy is $70 \%$ and $S p 80 \%$ but with high uncertainty $T P \sim$ Uniform $(0,1.00)$, Se $\sim$ Beta $(8.00,4.00)$ and $S p \sim$ Uniform $(9.00,2.00)$; Scenario 6) Assuming that $S e$ of the necropsy is $70 \%$ and $S p 80 \%$ but with low uncertainty $T P \sim$ Uniform $(0,1), S e \sim$ Beta $(71.0,31.0)$ and $S p \sim$ Uniform (86.0, 16.0); and finally (Scenario 7) $T P \sim \operatorname{Uniform}(0,1)$, Beta $(5.28,2.07)$ and Beta $(21.20,2.06)$ which correspond to our beliefs about necropsies. 
Table 1

Estimates of parameters in the Bayesian binomial model using different prior distributions for TP, Se and Sp of necropsy to identify bovine tuberculosis.

\begin{tabular}{|c|c|c|c|}
\hline Scenario & Prior distribution & Posterior mean \% & IP 95\% \\
\hline \multirow[t]{3}{*}{ Scenario 1} & $T P \sim$ Uniform $(0,1)$ & Did not converge & - \\
\hline & Se $\sim$ Uniform $(0,1)$ & Did not converge & - \\
\hline & $S p \sim \operatorname{Uniform}(0,1)$ & Did not converge & - \\
\hline \multirow[t]{3}{*}{ Scenario 2} & $T P \sim$ Uniform $(0,1)$ & 1.11 & $0.005-4.69$ \\
\hline & $\mathrm{Se} \sim$ Uniform $(0.51,0.98)$ & 71.89 & $68.80-94.60$ \\
\hline & $S p \sim$ Uniform $(0.80,0.90)$ & 98.22 & $98.08-99.64$ \\
\hline \multirow[t]{3}{*}{ Scenario 3} & $T P \sim$ Uniform $(0,0.10)$ & 1.83 & $0.008-4.40$ \\
\hline & $\mathrm{Se} \sim$ Uniform $(0.5,1.0)$ & 72.04 & $50.87-98.26$ \\
\hline & $S p \sim$ Uniform $(0.7,1.0)$ & 98.74 & 97.27-99.99 \\
\hline \multirow[t]{3}{*}{ Scenario 4} & $T P \sim$ Uniform $(0,0.05)$ & 1.95 & $0.01-4.50$ \\
\hline & $\mathrm{Se} \sim$ Uniform $(0.4,1.0)$ & 66.11 & $41.0-97.7$ \\
\hline & $S p \sim$ Uniform $(0.6,1.0)$ & 98.71 & $97.7-99.8$ \\
\hline \multirow[t]{3}{*}{ Scenario 5} & $T P \sim$ Uniform $(0,1)$ & 1.50 & $0.005-4.30$ \\
\hline & $S e \sim \operatorname{Beta}(8.0,4.0)$ & 63.63 & $34.63-87.83$ \\
\hline & $S p \sim \operatorname{Beta}(9.0,2.0)$ & 98.31 & $97.05-99.65$ \\
\hline \multirow[t]{3}{*}{ Scenario 6} & $T P \sim$ Uniform $(0,1)$ & 0.3 & $0.01-1.25$ \\
\hline & $S e \sim$ Uniform $(71,31)$ & 69.28 & $60.01-78.03$ \\
\hline & $S p \sim$ Uniform $(86,16)$ & 96.86 & $95.00-97.7$ \\
\hline \multirow[t]{3}{*}{ Scenario 7} & $T P \sim$ Uniform $(0,1)$ & 1.50 & $0.005-4.69$ \\
\hline & Se $\sim$ Uniform $(5.28,2.07)$ & 67.02 & $68.8-94.6$ \\
\hline & $S p \sim$ Uniform $(21.20,2.06)$ & 98.34 & $97.08-99.64$ \\
\hline
\end{tabular}

The agreement among the different laboratory-based diagnostic methods applied in this study was assessed by Cohen kappa statistic under cluster sampling (svykappa function) under $\mathrm{R}$ environment, described by Lumley (2004), which is the approach used to asses different tests without assuming that one is the best. The results obtained were classified according to the Altman scale to give a grade of significance (i.e., $>0.80$ : very good agreement, 0.61-0.80: good agreement, 0.41-0.60: moderate agreement, 0.21-0.40: fair agreement, and $\leq 0.20$ : poor agreement) (Abraira, 2000). In addition, the Se and Sp of histopathology, microscopy, and PCR were calculated taking the in vitro culture as a gold standard test. The $95 \%$ confident intervals (CI) were estimated for Se and Sp of each test.

\section{Results}

The apparent prevalence of gross visible lesions found by veterinary inspection was $2.33 \%(95 \% \mathrm{CI}=1.37-3.73$ ) and $2.42 \%(95 \% \mathrm{CI}=1.41-3.84)$ for the 2007 and 2008 surveys respectively. The TP was calculated to be $1.50 \%$ (95\% PI $=0.005-4.69)$ taking into account our prior believes related with the characteristic of this test. The estimated Se and Sp of necropsy in this study were $67.02 \%$ (95\% PI = 29.39-94.58) and 98.34\% (95\% PI=97.08-99.64), respectively. The estimates of the TP did not show important differences under several constrains, they were around $1.5 \%$, although when constrains had low uncertainty (scenario 6) the estimates of TP was lower. The estimates for $S p$ of necropsy were in general consistent and high. The estimates for Se of necropsy varied according to the constrictions and wide intervals were found (Table 1).

Macroscopically, we observed yellowish granulomatous tubercles in mediastinal (51.32\%), tracheobronchial (23.68\%), hepatic (11.84\%), and retropharyngeal $(9.21 \%)$ lymph nodes. Only one animal showed visible lung lesions. Also, the five CITT reactors showed visible lesions in thoracic lymph nodes, but not in the lungs.
From the 94 specimens, 31 yielded one or more positive results in the laboratory (Table 2): all 24 positive lymph nodes from 15 cattle showed visible lesions ( 8 bronchial, 7 mediastinal, 3 hepatic, 3 mammary, 2 retropharyngeal, and 1 scapular lymph node), versus only one of the 7 (14.28\%) positive lung tissues (Table 2). Fourteen of 31 specimens yielded a positive result in only a single test, 6 scored positive in 2 tests, 6 in 3 tests, and 5 had a positive result in all 4 tests applied.

On the animal level, this resulted in the detection of $M$. bovis in $51.5 \%(17 / 33)$ of the suspected animals. In 7 animals, only one specimen was found positive, whereas the remaining animals had $2-4$ positive specimens.

Histopathology examination allowed for the identification of BTB in 27.3\% (9/33) of the suspected animals. It showed focal necrosis, distrophic calcification and/or Langhans- and foreign body-type giant cells in a total of 12 biopsies. Giant cells were identified in the lung sample showing gross lesions and in 3 mediastinal lymph nodes. Necrosis and/or calcification were more frequently observed (11 samples). In the remaining animals (24/33), a variety of lesions was identified in lungs (chronic interstitial pneumonia $65.7 \%$, atelectasis $17.1 \%$, emphysema $8.6 \%$, granulomatous pneumonia 5.7\% and bronchioloalveolar carcinoma $2.9 \%$ ), and lymph nodes (caseous lymphadenitis $38.3 \%$, follicular hyperplasia $31.9 \%$, lymphoma $8.5 \%$, oedema with infiltrate of macrophages $6.3 \%$, other lesions $4.2 \%$, and no significant lesions $10.6 \%$ ).

AFB were detected in ZN-stained smears from 33.3\% (11/33) of suspected animals. Fourteen (14) of 94 smears were positive: 4 from lung samples and 10 from lymph nodes, mainly bronchial and mediastinal (Table 2). However, the number of AFB detected per smear was very low, with a maximum of 10 . Five cases had more than 3 AFB per slide but in 9 slides only 1 or 2 AFB were observed.

In vitro culture proved the most sensitive method in this study. M. bovis was isolated from $36.4 \%$ (12/33) suspected cattle. Bacilli were grown in 23 samples after about 7 weeks, and on Stonebrink medium only. The colonies were 
Table 2

Distribution of positive laboratory results for bovine tuberculosis observed in 31 specimens from 17 different animals taken from dairy cattle at the slaughterhouse of Machachi, Ecuador.

\begin{tabular}{|c|c|c|c|c|c|c|c|c|}
\hline Area & Animal identification & Farm & Specimen & Visible lesion & Smear ZN & Culture ST & PCR 16S rRNA & Histo-pathology \\
\hline \multirow[t]{18}{*}{ Machachi } & 1 & A & Bronchial LN & Yes & Positive & - & - & - \\
\hline & 5 & B & Lung & No & - & - & Positive & - \\
\hline & \multirow[t]{2}{*}{8} & \multirow[t]{2}{*}{ C } & Bronchial LN & Yes & - & Positive & - & Positive \\
\hline & & & Retropharyngeal LN & Yes & - & - & - & Positive \\
\hline & 33 & $\mathrm{C}$ & Lung & No & - & Positive & & \\
\hline & \multirow[t]{5}{*}{14} & \multirow[t]{5}{*}{$\mathrm{C}$} & Retropharyngeal LN & Yes & - & Positive & - & Positive \\
\hline & & & Bronchial LN & Yes & - & Positive & Positive & Positive \\
\hline & & & Hepatic LN & Yes & - & Positive & Positive & - \\
\hline & & & Mammary LN & Yes & - & Positive & Positive & - \\
\hline & & & Lung & No & Positive & Positive & Positive & - \\
\hline & \multirow[t]{2}{*}{23} & \multirow[t]{2}{*}{ C } & Lung & No & Positive & - & - & - \\
\hline & & & Mediastinal LN & Yes & - & Positive & - & - \\
\hline & \multirow[t]{3}{*}{13} & \multirow[t]{3}{*}{$\mathrm{D}$} & Hepatic LN & Yes & - & Positive & Positive & Positive \\
\hline & & & Bronchial LN & Yes & - & Positive & - & - \\
\hline & & & Lung & No & - & - & Positive & - \\
\hline & 26 & $\mathrm{D}$ & Mediastinal LN & Yes & Positive & Positive & Positive & Positive \\
\hline & 30 & $\mathrm{D}$ & Mediastinal LN & Yes & - & Positive & - & - \\
\hline & 32 & $\mathrm{D}$ & Mediastinal LN & Yes & - & - & - & Positive \\
\hline \multirow[t]{3}{*}{ Tambillo } & \multirow[t]{2}{*}{12} & \multirow[t]{2}{*}{$\mathrm{E}$} & Bronchial LN & Yes & Positive & Positive & - & - \\
\hline & & & Lung & No & Positive & Positive & Positive & Positive \\
\hline & 25 & $\mathrm{~F}$ & Mammary LN & Yes & Positive & - & - & - \\
\hline \multirow[t]{5}{*}{ Aloasi } & \multirow[t]{3}{*}{16} & \multirow[t]{3}{*}{ G } & Scapular LN & Yes & - & Positive & - & - \\
\hline & & & Bronchial LN & Yes & Positive & Positive & Positive & - \\
\hline & & & Mediastinal LN & Yes & - & Positive & - & Positive \\
\hline & 31 & G & Mammary LN & Yes & Positive & - & - & - \\
\hline & 28 & $\mathrm{H}$ & Bronchial LN & Yes & Positive & Positive & Positive & - \\
\hline \multirow[t]{4}{*}{ Aloag } & \multirow[t]{4}{*}{19} & \multirow[t]{4}{*}{ I } & Lung & Yes & Positive & Positive & Positive & Positive \\
\hline & & & Mediastinal LN & Yes & Positive & Positive & Positive & Positive \\
\hline & & & Bronchial LN & Yes & Positive & Positive & Positive & - \\
\hline & & & Hepatic LN & Yes & - & Positive & - & - \\
\hline Chaupi & 20 & $\mathrm{~J}$ & Mediastinal LN & Yes & Positive & Positive & Positive & Positive \\
\hline
\end{tabular}

ZN = Ziehl-Neelsen, $\mathrm{ST}$ = stonebrink, LN = lymph node.

obtained from 19 lymph node and 4 lung specimens, all positive $M$. bovis isolates were confirmed by spoligotyping. No mycobacteria other than $M$. bovis were detected by culture.

Nested PCR detected 27.23\% (9/33) positive animals. M. tuberculosis complex DNA was amplified in 15 of 94 samples: 10 lymph nodes and 5 lung biopsies (Table 2). Negative DNA-extraction and PCR controls yielded a negative result in all PCR runs.

Survey kappa analysis of the various laboratory tests revealed a substantial concordance between culture and PCR $(\kappa=0.61)$, a moderate concordance between culture and histopathology $(\kappa=0.49)$, culture and microscopy $(\kappa=0.44)$, PCR and microscopy $(\kappa=0.47)$, and PCR with histopathology $(\kappa=0.44)$ (Table 3$)$. A low concordance was observed between microscopy and histopathology $(\kappa=0.20)$.
Compared to in vitro culture, the 3 remaining techniques had a low sensitivity to detect BTB. The Se of PCR (56.5\%; 95\% $\mathrm{CI}=34.4-76.8)$ was higher than that of microscopy (43.5\%; 95\% CI = 23.2-65.5) and histopathology (43.5\%; 95\% $\mathrm{CI}=23.2-65.5)$. Specificities were much higher with $94.4 \%$ (95\% CI $=86.2-98.4$ ) for PCR and microscopy, and $97.2 \%$ (95\% CI =90.2-99.6) for histopathology.

\section{Discussion}

The prevalence of BTB, as determined by the detection of gross visible lesions in slaughtered animals, was similar in 2007 and 2008 (2.32\% and 2.41\%, respectively). However, the true prevalence, taking into account the Se (83.33\%) (Norby et al., 2004) and Sp (95\%) calculated for this method, was lower (1.50\%). As this study was the first of its kind in the Mejia canton, we cannot compare our

Table 3

Concordance analysis by survey sampling Kappa of the laboratory tests applied to diagnose BTB from specimens taken at the abattoir of the Mejia canton-Ecuador during 2007 and 2008.

\begin{tabular}{|c|c|c|c|c|c|c|c|c|}
\hline \multirow[t]{2}{*}{ Tests } & \multicolumn{2}{|c|}{ Microscopy } & \multicolumn{2}{|l|}{ Culture } & \multicolumn{2}{|l|}{ PCR } & \multicolumn{2}{|c|}{ Histopathology } \\
\hline & $\kappa$ value & Std error & $\kappa$ value & Std error & $\kappa$ value & Std error & $\kappa$ value & Std error \\
\hline Microscopy & 1 & na & & & & & & \\
\hline Culture & 0.44 & 0.12 & 1 & na & & & & \\
\hline PCR & 0.47 & 0.15 & 0.61 & 0.08 & 1 & na & & \\
\hline Histopathology & 0.20 & 0.14 & 0.48 & 0.06 & 0.44 & 0.13 & 1 & na \\
\hline
\end{tabular}

$\kappa:$ Kappa, na: not applicable. 
results with previous data of this region, even though it is the most important dairy region in the north of Ecuador. Abattoir surveys performed in other provinces showed a lower prevalence: $0.12 \%$ and $0.46 \%$ in Guayas, and $0.21 \%$ in Santo Domingo de los Sáchilas (Mata, 1973; Cueto and Suárez, 1993; Coloma, 2000). However, these studies which were never officially published - were carried out in meat production regions and therefore are not comparable with our data from dairy cattle as shown by data from other countries. In Mexico, an abattoir survey revealed the presence of gross lesions typical for BTB in $16 \%$ of dairy cattle (Milian-Suazo et al., 2000), whereas another survey revealed significantly less gross lesions among beef cattle $(0.05 \%)$ (Brown and de Anda, 1998). This difference between dairy and beef cattle has been observed in different abattoirs throughout Ecuador, and it was attributed to several factors such as cattle density, management practices and breed; however, data have never been published (personal communication). In Ecuadorian dairy industry, imported European breeds have been used to improve milk production, i.e. Holstein Friesian, which is less resistant to BTB than Zebu (Omer et al., 2001; Ameni et al., 2007; Kazwala et al., 2001).

Compared to the recently observed CITT-based prevalence data among dairy cattle from the Mejia canton (Proaño-Pérez et al., 2009), our veterinary-inspectionbased prevalence was lower. This could reflect the lower sensitivity of post-mortem examination (Norby et al., 2004), implicating that a high number of animals might be classified as negative by this method. Routine abattoir inspection can be affected by the method employed, the anatomical sites examined and the stage of infection (Corner, 1994); it will fail to detect infected animals if lesions are present in tissues not being inspected. Since the veterinary inspection in our survey was done in a very comprehensive way, we believe that the early stage of infection played a role in the low detection rate. During our abattoir survey only one of the 5 bovine CITT reactors had evident gross lesions; the rest showed only minor lesions in thoracic lymph nodes. Three of the latter were identified as CITT-reactors in the year of slaughter, and therefore might be at the early stage of infection. The two remaining animals were CITT-reactors in two consecutive years and slaughtered afterwards; one of them showed characteristics of advanced disease. Nevertheless, BTB was confirmed by laboratory tests in all CITT-reactors. These findings confirm that animals only show evident characteristics in an advanced stage of the disease (Corner, 1994), although the symptoms of the disease are not pathognomonic. On the other hand, our data also confirm that M. bovis can be isolated from animals without gross lesions, including lungs (Whipple et al., 1996; Teklul et al., 2004).

Gross visible lesions may be caused by other organisms as well, and also NTM may constitute a confounding factor. In Tanzania, Cleaveland and colleagues (2007) identified $M$. terrae, M. avium, M. chelonae, M. gordonae, M. fortuitum, $M$. flavescens and $M$. smegmatis in samples from slaughtered cattle with visible lesions; however, the clinical relevance of the isolation of these environmental mycobacteria needs to be confirmed. In Ecuador, the presence of M. aviumintracellulare-scrofulaceum, M. gordonae, M. szulgai and $M$. celatum was reported in slaughtered dairy cattle (ProañoPerez et al., 2006). Therefore, the identification of the species plays a crucial role in the final diagnosis of the disease. We did not isolate NTM in the present study.

The combined use of microscopy, in vitro culture, PCR and histopathology identified BTB in 51.5\% (17/33) of the suspected animals. Nevertheless, only 6 of these animals were positive by all the laboratory methods used.

M. bovis was identified by in vitro culture in $36.34 \%$ of the suspected cattle. This is low compared to studies from Mexico and Argentina. In Mexico, BTB infection was confirmed by culture in 59\% of cattle from 6 important dairy regions (Milian-Suazo et al., 2000), and in the Province of Santa Fé, Argentina, with $83 \%$ of samples showing visible lesions (Latini et al., 1997). The Se of detection by culture can be reduced due to the applied decontamination procedure or pre-analytical storage conditions of the samples, affecting the viability of the Mycobacteria (Palomino and Portaels, 1998). Freezing-thawing cycles proved to reduce the viability of mycobacteria significantly (Portaels et al., 1988). As our specimens underwent two freeze-thaw cycles, part of the bacilli may have been killed and therefore could not be isolated. AFB were detected in 14 of 94 specimens, but in 4 of them the presence of $M$. bovis could not be confirmed by culture. This might be attributed to the suboptimal storage conditions not ensuring survival of the bacteria. Nevertheless, our culture positivity rate was still higher than that observed in some other studies. In Brazil, culturing of $M$. bovis was successful in $18 \%$ of the samples (Pires de Araújo et al., 2005); no information was given on the storage conditions of the investigated samples.

The detection rate by PCR was even lower in our study. Applied on decontaminated tissue samples, it could detect BTB in $27.3 \%$ of suspected animals. In Brazil, $18 \%$ of cattle showing gross lesions yielded a positive PCR (Pires de Araújo et al., 2005). The Se of nucleic acid amplification can be influenced by different factors, such as insufficient quantity of bacilli or the presence of inhibitors hampering the polymerase (Mangiapan et al., 1996; Pires de Araújo et al., 2005; Cardoso et al., 2009). In Brazil, comparison between different concentrations and volumes of DNA samples showed that the percentage of PCR-positive lymph nodes increased from $39.4 \%$ to $54.5 \%$ after re-analysis of the initially negative samples using a 1:2 dilution of the suspension and 2,5 $\mu$ l instead of $1 \mu \mathrm{l}$ (Cardoso et al., 2009). In our study, we used $10 \mu$ l of undiluted DNA extract for the PCR, implicating that the sensitivity of our PCR might increase by the use of diluted DNA extracts, thus minimizing the effect of possible inhibitors.

We observed a good agreement between culture and PCR $(\kappa=0.61)$, implicating that a high number of samples yielded a positive result by both tests, and confirming that culture and PCR are the most important diagnostic tools for the diagnosis of BTB in dairy areas (Cardoso et al., 2009).

Histopathology showed BTB compatible images in $27.3 \%$ of the cattle with macroscopic lesions. Demelash et al. (2009) showed that the Se of histopathology diagnosis can be affected by the technique used and the number of slides examined. In our study, two slides per specimen were examined, i.e., after HE and after ZN staining. On the other 
hand, only 5 of the 9 animals identified by histopathology were positive by all laboratory tests.

The diagnostic accuracy of a test is primarily defined by its $S e$ and $S p$. However, these parameters can be influenced by minor changes occurring when processing samples. In this study, culture was considered the gold standard method to estimate the Se and $S p$ of the remaining diagnostic tests. It is important to consider that all samples were paucibacillary and pre-analytical sample conditions were suboptimal for culture because of the two freezingthawing cycles. Therefore, the observed sensitivities of PCR (56.5\%), microscopy and histopathology (43.5\% each) could be overestimated. Microscopy is known to have a low Se, as it requires 5000 to 10,000 bacilli/mL of sample to yield a positive result. The Se of PCR and histopathology could be influenced by factors described above.

In routine conditions, it is not feasible to apply all these laboratory tests for all samples, given the high cost and labour required. Therefore, the best strategy should be chosen to confirm the suspected cases when implementing a BTB control program in Ecuador. The results obtained in this study suggest that PCR is a good alternative for culture, yielding results in a much shorter time. However, as it counts for culture, PCR needs to be performed by trained personal in an appropriate, quality-ensured laboratory. On the other hand, microscopy is rapid, easy, and cheap, and it can be implemented in resource-poor settings (Hirao et al., 2007). Because of its low sensitivity, all smearnegative samples should be retested by culture and/or PCR. A possible strategy to perform post-mortem diagnosis for BTB could be as follows: veterinary inspection, sampling of tissues showing gross visible lesions and lungs, smear microscopy to detect AFB, and PCR on all smear-negative samples.

Our second objective was to study and characterize the distribution of lesions observed in the organs from slaughtered cattle as a surrogate marker for the possible route of transmission and stage of disease (Phillips et al., 2003). During our survey, macroscopic lesions were found in mediastinal (51.32\%), tracheobronchial (23.68\%), hepatic (11.84\%) and retropharyngeal lymph nodes (9.21\%), and in other sites (3.95\%). Mild lesions in lungs were found in only one slaughtered bovine. Similar observations were published in the United States and Iran, where no gross lesions suggestive of BTB were observed in lungs from dairy cattle, but frequently in lymph nodes of the thoracic region (Whipple et al., 1996; Tadayon et al., 2008). On the contrary, affection of lungs and other organs has been reported in cattle in Africa. In Ethiopia, 84\% of visible lesions were found in the lungs and thoracic lymph nodes (Teklul et al., 2004). In Mali, $79 \%$ of the animals had confirmed lesions in lungs, and the infection with $M$. bovis was highly associated with these lesions ( $p<0.001$ ) (Müller et al., 2008). However, in Tanzania, visible lesions were mainly found in the gastrointestinal tract (61.3\%) (Cleaveland et al., 2007); these differences could be attributed to the breeds involved in the studies.

It is important to also consider that different $M$. bovis genotypes may differ in pathogenesis and thereby affect the development of lesions (Goodchild et al., 2003; Ameni et al., 2007; Oloya et al., 2007). In our study all ani- mals with macroscopic lesions were Holstein Friesian and infected by the same strain (SB0980; Proaño-Pérez et al., in preparation). The observed inter-animal heterogeneity of macroscopic and microscopic lesions therefore most likely represents the individual diversity of pathological evolution of BTB (Meikle et al., 2007).

The macroscopic lesions found in dairy cattle slaughtered during this survey suggest that the most important route of transmission among the cattle studied was through respiratory tract.

\section{Conclusion}

In conclusion, our data demonstrate that veterinary inspection in combination with laboratory-based analyses is useful to document the presence of BTB, and they urge for the implementation of a national BTB control program. It should combine in vivo skin testing before slaughter to identify early infections with $M$. bovis, with extended postmortem inspection including laboratory-based diagnosis. These activities should be performed by qualified veterinarians and technicians, following strict safety procedures to avoid human infections. Veterinary inspection needs to be implemented as a routine procedure in all abattoirs located in areas with a high cattle density. However, this can only be achieved if BTB is declared an important disease for animal and human health in Ecuador, and the required financial support is provided to support inspections, testing and compensation for losses.

\section{Acknowledgements}

The authors gratefully acknowledge the financial support from 'Commission Universitaire pour le Développement' (CUD), University of Liege - Project PIC. We also thank Dr. Antonio Viteri and all slaughterhouse workers in the Mejia canton for their collaboration during our survey. Finally, we thank the important contribution of the Reviewers and Associate Editor from this Journal.

\section{References}

Abraira, V., 2000. El indice Kappa. Semergen 27, 247-249.

Ameni, G., Aseffa, A., Engers, H., Young, D., Gordon, S., Hewinson, G., Vordemeier, M., 2007. High prevalence and increased severity of pathology of bovine tuberculosis in Holsteins compared to zebu breeds under field cattle husbandry in Central Ethiopia. Clin. Vacc. Immunol. 14, 1356-1361.

Berkvens, D., Speybroeck, N., Praet, N., Adel, A., Lesaffre, D., 2006. Estimating disease prevalence in Bayesian framework using probabilistic constraints. Epidemiology 17, 145-153.

Branscum, A.J., Gardner, I.A., Johnson, W.O., 2005. Estimation of diagnostic test sentitivity and specificity through Bayesian modelling. Prev. Vet. Med. 68, 145-163.

Branscum, A.J., Gardner, I.A., Johnson, W.O., 2004. Bayesian modelling of animal and herd level prevalences. Prev. Vet. Med. 66, 101-112.

Brown, W.H., de Anda, J.H., 1998. Tuberculosis in adult beef cattle of Mexican origin shipped direct-to-slaughter into Texas. J. Am. Vet. Med. Assoc. 212, 557-559.

Cardoso, M.A., Cardoso, R.F., Hirata, R.D.C., Hirata, M.H., Leite, C.Q.F., Santos, A.C.B., Siqueira, V.L.D., Okano, W., Rocha, N.S., Lonardoni, M.V.C., 2009. Direct detection of Mycobacterium bovis in bovine lymph nodes by PCR. Zoonoses Public Health 56, 465-470.

Cleaveland, S., Shaw, D.J., Mfinanga, S.G., Shirima, G., Kazwala, R.R., Eblate, E., Sharp, M., 2007. Mycobacterium bovis in rural Tanzania: risk factors for infection in human and cattle populations. Tuberculosis 87, 30-43. 
Collins, J.D., 2006. Tuberculosis in cattle: strategic planning for the future. Vet. Microbiol. 112, 369-381.

Coloma, L., 2000. Determinación de tuberculosis en bovinos sacrificados en el matadero municipal de Santo Domingo de los Colorados [Thesis end of studies]. Guayaquil: Faculty of Veterinary Medicine, Agraria University of Ecuador.

Corner, L.A., 1994. Post mortem diagnosis of Mycobacterium bovis infection in cattle. Vet. Microbiol. 40, 53-63.

Cosivi, O., Grange, J.M., Daborn, C.J., Raviglione, M.C., Fujikura, T., Cousins, D., Robinson, R.A., Huchzermeyer, H.F., de Kantor, I., Meslin, F.X., 1998 Zoonotic tuberculosis due to Mycobacterium bovis in developing countries. Emerg. Infect. Dis. 4, 59-70.

Cueto, N., Suárez, M., 1993. Porcentaje de lesiones tuberculosas encontradas en animales de abasto a nivel de matadero y su verificación con diagnostico bacteriológico [Thesis end of studies]. Guayaquil: Faculty of Veterinary Medicine, Agraria University of Ecuador.

Demelash, B., Inangolet, F., Oloya, J., Asseged, B., Badaso, M., Yilkal, A., Skjerve, E., 2009. Prevalence of bovine tuberculosis in Ethiopian slaughter cattle based on post-mortem examination. Trop. Anim. Health Prod. 41, 755-765.

Enoe, C., Georgiadis, M.P., Johson, W.O., 2000. Estimation of sensitivity and specificity of diagnostic test and disease prevalence when the true diseases state is unknown. Pre. Vet. Med. 45, 61-81.

Goodchild, A.V., De la Rua-Domenech, R., Palmer, S., Dale, J., Gordon, S.V., Hewinson, R.G., Clifton-Hardley, R.S., 2003. Association between molecular type and epidemiological features of Mycobacterium bovis in cattle. In: The Society for Veterinary Epidemiology and Preventive Medicine, University of Warwick, pp. 45-59.

Goodchild, A.V., Clifton-Hadley, R.S., 2001. Cattle-to-cattle transmission of Mycobacterium bovis. Tuberculosis (Edinb). 81, 23-41.

Hirao, S., Yassin, M.A., Khamofu, H.G., Lawson, L., Cambanis, A., Ramsay, A. Cuevas, L.E., 2007. Same-day smears in the diagnosis of tuberculosis. Trop. Med. Int. Health. 12, 1459-1463.

Kamerbeek, J., Schouls, L., Kolk, A., Van Agterveld, M., Van Soolingen, D. Kuijper, S., Bunschoten, A., Molhuizen, H., Shaw, R., Goyal, M., Van Embden, J., 1997. Simultaneous detection and strain differentiation of Mycobacterium tuberculosis for diagnosis and epidemiology. J. Clin. Microbiol. 35, 907-914.

Kazwala, R., Kambarage, D., Daborn, C., Nvange, J., Jiwa, S., Sharp, J., 2001. Risk factors associated with the occurrence of bovine tuberculosis in cattle in the Southern Highlands of Tanzania. Vet. Res. Commun. 25, 609-614.

Latini, O., Canal, A.M., Ferrara, M.E., Sequeira, M.D., Sequeira, G., Bagnaroli, R., Torres, P., 1997. Confiabilidad en la determinación de prevalencia de infección por Mycobacterium bovis en ganado bovino por decomisos en frigoríficos. Arch. de Med. Vet. 29, 197-204.

Lumley, T., 2004. Analysis of complex survey samples. J. Stat. Softw. 9, 8.

Mangiapan, G., Vokurka, M., Schouls, L., Cadranel, J., Lecossier, D., van Embden, J., Hance, A.J., 1996. Sequence capture-PCR improves detection of mycobacterial DNA in clinical specimens. J. Clin. Microbiol. 34, $1209-1215$

Mata, M., 1973. Determinación del índice de bovinos tuberculosos que se sacrifican en el matadero municipal de la cuidad de Guayaquil [Thesis end of studies]. Guayaquil: Faculty of Veterinary Medicine, University of Guayaquil.

Meikle, V., Schneider, M., Azenzo, G., Zumárraga, M., Magnano, G., Cataldi, A., 2007. Individual animals of a cattle herd infected with the same Mycobacterium bovis genotype shows important variations in bacteriological, histopathological and immune response parameters. Zoonoses Public Health 54, 86-93.

Milian-Suazo, F., Salman, M.D., Ramirez, C., Payeur, J.B., Rhyan, J.C., Santillan, M., 2000. Identification of tuberculosis in cattle slaughtered in Mexico. Am. J. Vet. Res. 61, 86-89.
Müller, B., Steiner, B., Bonfoh, B., Fané, A., Smith, N.H., Zinsstag, J., 2008 Molecular characterisation of Mycobacterium bovis isolated from cattle slaughtered at the Bamako abattoir in Mali. BMC Vet. Res. 4 26.

Neill, S.D., Pollock, J.M., Bryson, D.B., Hanna, J., 1994. Pathogenesis of Mycobacterium bovis infection in cattle. Vet. Microbiol. 40, 41-52.

Norby, B., Bartlett, P.C., Fitzgerald, S.D., Granger, L.M., Bruning-Fann, C.S., Whipple, D.L., Payeur, J.B., 2004. The sensitivity of gross necropsy, caudal fold and comparative cervical tests for the diagnosis of bovine tuberculosis. J. Vet. Diagn. Invest. 16, 126-131.

Oloya, J., Kazwala, R., Lund, A., Opuda-Asibo, J., Demelash, B., Skjerve, E., Johansen, T.B., Djønne, B., 2007. Characterisation of mycobacteria isolated from slaughter cattle in pastoral regions of Uganda. BMC Microbiol. 7, 95.

Omer, M.K., Skjerve, E., Woldehiwet, Z., Holstad, G., 2001. A cross-sectional study of bovine tuberculosis in dairy farms in Asmara, Eritrea. Trop. Anim. Health Prod. 33, 295-303.

Palomino, J.C., Portaels, F., 1998. Effects of decontamination methods and culture conditions on viability of Mycobacterium ulcerans in the BACTEC System. J. Clin. Microbiol. 36, 402-408.

Parks, L.C., 1997. Microbiological Media, Second edition. CRC Press, New York, pp. 774-776.

Phillips, C.J., Foster, C.R., Morris, P.A., Teverson, R., 2003. The transmission of Mycobacterium bovis infection to cattle. Res. Vet. Sci. 74, 1-15.

Pires de Araújo, C., Leite, C.Q., Andrade de Prince, K.A., Jorge, K., Osório, A.L., 2005. Mycobacterium bovis identification by a molecular method from post-mortem inspected cattle obtained in abattoirs of Mato Grosso do Sul, Brazil. Mem. Inst. Oswaldo Cruz. 100, 749-752.

Pollock, J.M., Rodgers, J.D., Welsh, M.D., McNair, J., 2006. Pathogenesis of bovine tuberculosis: the role of experimental models of infection. Vet. Microbiol. 112, 141-150.

Portaels, F., Realini, L., Bauwens, L., Hirschel, B., Meyers, W.M., de Meurichy, W., 1996. Mycobacteriosis caused by Mycobacterium genavense in birds kept in a zoo: 11-year survey. J. Clin. Microbiol. 34, 319-323.

Portaels, F., Fissette, K., De Ridder, K. Macedo, P.M., De Muynck, A., Silva, M.T., 1988. Effects of freezing and thawing on the viability and the ultrastructure of in vivo grown mycobacteria. Int. J. Lepr. Other Mycobact. Dis. 56, 580-587.

Proaño-Pérez, F., Benítez-Ortiz, W., Celi-Erazo, M., Ron-Garrido, L., Benítez-Capistros, R., Portaels, F., Rigouts, L., Linden, A., 2009. Comparative intradermal tuberculin test in dairy cattle in the north of Ecuador and risk factors associated with bovine tuberculosis. Am. J. Trop. Med. Hyg. 81, 1103-1109.

Proaño-Perez, F., Rigouts, L., Brandt, J., Dorny, P., Ron, J., Chavez, M., Rodriguez, R., Fissette, K., Van Aerde, A., Portaels, F., Benitez-Ortiz, W., 2006. Preliminary observations on Mycobacterium spp. in dairy cattle in Ecuador. Am. J. Trop. Med. Hyg. 75, 318-323.

Spiegelhalter, D., Thomas, A., Best, N., Gilks, W., 1996. BUGS: Bayesian Inference Using Gibbs Sampling, Version 0.50. MRC Biostatistics Unit, Cambridge. http://www.mrc-bsu.cam.ac.uk/ bugs/winbugs/contents.shtml.

Tadayon, K., Mosavari, N., Sadeghi, F., Forbes, K.J., 2008. Mycobacterium bovis infection in Holstein Friesian cattle, Iran. Emerg. Infect. Dis. 14, 1919-1921.

Teklul, A., Asseged, B., Yimer, E., Gebeyehu, M., Woldesenbet, Z., 2004. Tuberculous lesions not detected by routine abattoir inspection: the experience of the Hossana municipal abattoir, southern Ethiopia. Rev. Sci. Tech. 23, 957-964.

Whipple, D.L., Bolin, C.A., Miller, J.M., 1996. Distribution of lesions in cattle infected with Mycobacterium bovis. J. Vet. Diagn. Invest. 8, 351-354. 